\title{
Demand Side Management and Demand Response under Smart Grid Framework
}

\author{
Sang Ying Jun ${ }^{1, a}$, Zhao Xuan ${ }^{2, b}$ and Geng Wei ${ }^{3, c}$ \\ ${ }^{1}$ Department of Automation Huaiyin Institute of Technology Huaian,Jiangsu Province,China \\ ${ }^{2}$ Department of Automation Huaiyin Institute of Technology Huaian,Jiangsu Province,China \\ ${ }^{3}$ State grid jiangsu electric power maintenance branch company,Xuzhou,Jiangsu Province,China \\ asangyingj@163.com, ${ }^{b}$ 965536971@qq.com
}

\section{Keywords: Smart Grid; Demand Side Management; Demand Response}

Abstract:In this paper, the demand side management in the framework of smart grid is introduced., and analyzes the connotation of demand side management in Smart Grid. In addition, this paper focuses on the relationship between demand side management and demand response, analyzes the electricity saving benefits of demand side management in Huaian, and puts forward some suggestions on the development of demand side management and demand response in the framework of smart grid.

\section{INTRODUCTION}

Enter twenty-first Century, the energy development goals tend to diversify and clean.In order to achieve the coordinated development of energy and economy, many countries around the world have begun to study the smart grid.The research and development of smart grid technology is a major reform and innovation for the development of power system technology.

Compared with traditional power grid, smart grid has the key characteristics of allowing and promoting the implementation of demand-side response and user load to participate in the operation of power grid and power market, and placing users at the core of energy decision-making. Thus, users and loads can participate in the real-time balance of supply and demand more widely, so as to change the situation that the supply side played a leading role in the power industry in the past.The implementation of demand side management can avoid, reduce or defer investment in power generation, transmission and distribution capacity, reduce fuel consumption, improve environmental quality, and reduce greenhouse gas emissions[1]. Thus, the demand side management technology has a very important position in the smart grid.

\section{DEMAND SIDE MANAGEMENT UNDER SMART GRID FRAMEWORK}

\section{A. Demand Side Management}

DSM is mainly used to achieve the balance of power supply and demand, originated in 20 actual 70s.After a long time of exploration and research, DSM has become an important means for countries to respond to the energy problem.Since the introduction of the concept of DSM in China, we have implemented a series of related measures from the aspects of policy, incentive and technology development.March 2015, the CPC Central Committee and State Council issued a number of opinions on further deepening the reform of the power system, the active DSM and energy efficiency management, included in the five basic principles.DSM is a systematic project,it mainly considers two aspects, the first one is to reduce the maximum load of power system, trying to take the smaller new power installed capacity to reach the balance between power supply and demand; the second one is to try to cut down the power system of power generation and generation of fuel[2]. When converting primary energy such as fuel into electric energy and supplying electricity, the power system needs to have the appropriate generating power supply capacity and power supply to meet the needs of all kinds of users connected to the power network. 


\section{B. The Connotation of Demand Side Management in Smart Grid}

With the rapid development of the smart grid construction, the demand of DSM is gradually improved.DSM in smart grid will face the following technical changes: the whole network construction, the whole network management (full coverage, full collection, full prepaid)[3]. Therefore, DSM in smart grid is more extensive than the traditional power grid.

1) To achieve a good interaction between the grid and the user

The main characteristics and the goal of building the smart grid is to realize the "intelligent interactive",DSM in Smart Grid is no longer a simple power management, the power grid enterprises adopt a more comprehensive and reasonable time-sharing price policy, carry out real time pricing system, moreover,they release the relevant power grid operation to users, including real-time load, real-time power supply and so on.Combined with real-time power supply and their own needs, users choose the right power supply.At the same time, the users' real-time load can be monitored comprehensively under the smart grid. The smart meter recording the user's power consumption, and the information feedback to the power company, it is conducive to the dispatch center to grasp the real-time load situation, to carry on the short-term load forecast, and to ensure the timely supply of the load.

2) The User Side Distributed Generation Resources Brought into the Management Category Distributed energy is an important feature of smart grid, the comprehensive development of distributed green resources can effectively alleviate the current situation of coal power shortage。Each power supply mechanism switches between self-digestion power generation capacity and power on the grid according to self actual situation,or in the case of power grid enterprises need to power on the grid.Such as the rapid development of electric vehicle technology, it adopts the demand side management methods to deal with the problem of large-scale electric vehicle access to the grid,with the foreseeable improvement in battery performance, electric vehicles may not only be regarded as a load, but also can be used as a distributed energy storage device.Based on the concept of vehicle-to-grid(V2G), it is pointed out that electric vehicles can change their roles between absorbing and feedback electric energy in different operation states of power grid to complete charging or discharging.

\section{FROM DEMAND SIDE MANAGEMENT TO DEMAND RESPONSE}

DR is the indispensable, necessary and favorable response to power users corresponding to DSM[4].With the gradual development of the market, DR will gradually become the main means of DSM.The increase of DR provides better economic incentives,through price signal and incentive mechanism, users change their inherent power consumption habits and realize load transfer; at the same time, the DSM to DR programs can be fully developed.In addition, the development of smart grid provides powerful technical support for demand-side response, and promotes the development of demand-side response to a new level. Intelligent power grid and demand side response coordinated advance, can produce multi - faceted cooperation benefit .

The DR project is a new resource to participate fully in the electricity market.

a) In the design, operation and communication of the network, the user equipment and behavior are introduced, which can effectively stimulate the enthusiasm of the users to participate in DR project.

b) The implementation of DR mechanism makes full use of a wide range of seamless, real-time smart grid technology, it adopts intelligent methods to manage DR items, while makes the realization of intelligent monitoring and diagnosis of power grid operation.

c) By using the advanced market analysis tools and the intelligent scheduling system of the smart grid, the DR project can coordinate the market pricing and system scheduling management on different time scales, so as to promote the development of the power market[5]. 


\section{ANALYSIS ON ENERGY-SAVING BENEFIT OF IMPLEMENTING DEMAND-SIDE IN HUAIAN CITY}

\section{A. Energy saving evaluation parameters}

The total social electricity consumption of Huaian City from 2008 to 2017 is shown in figure 1 through data collection.

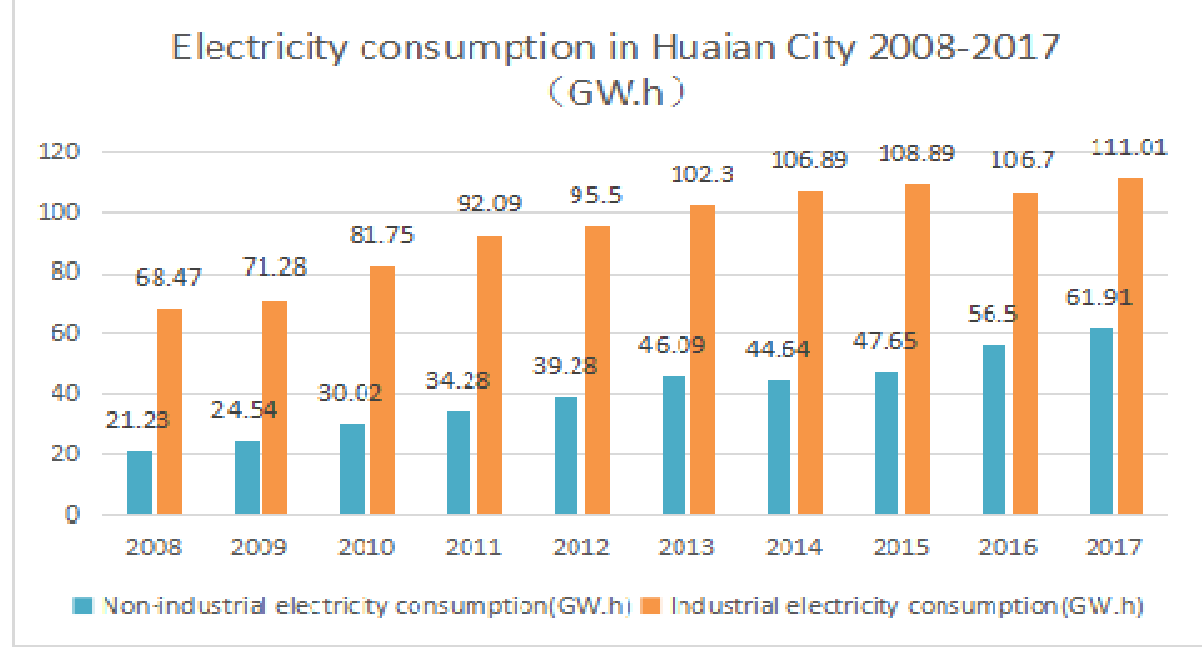

Fig.1 .Total social electricity consumption in Huaian City,2006-2017

Data from Huaian Power supply Company

Assuming that non-industrial power consumption is lighting, 30\% users in Huai'an power grid participate in demand-side management, then the participation rate of lighting energy saving $\omega_{n . z}=0.3$. At the same time, $20 \%$ users use electric drive to save electricity, that is to say, frequency conversion speed regulation is used to save electricity and the $\omega_{n . d}=0.2$. Generally, the power saving rate a of frequency conversion speed regulation $\lambda_{d}$ ranges from $15 \%$ to $50 \%$. Here, take $\lambda_{d}=15 \%$. In the case of the same luminous flux, the energy consumption of a LED lamp is only $1 / 10$ of that of an incandescent lamp, and a quarter of that of an energy-saving lamp, and the power saving rate of the ordinary incandescent lamp is replaced by that of the LED lamp $\lambda_{z}=0.9$. We take the loss coefficient of transmission and distribution $\alpha_{w}=0.06$ and Power consumption rate of coal-fired power plant $\beta=0.08$.

B. Estimated avoidable power

The following (1)-(5) are the formulas for calculating the amount of electricity that can be avoided after the implementation of DSM[6].

$\Delta W_{n . s}=\omega_{n . z} * \Delta W_{n . s . z}+\omega_{n . d} * \Delta W_{n . s . d}$,

$\Delta W_{n . s . d}=\frac{\Delta W_{d . b}}{\left(1-\alpha_{w}\right)(1-\beta)}$,

$\Delta W_{n . s . z}=\frac{\Delta W_{z . b}}{\left(1-\alpha_{w}\right)(1-\beta)}$,

$\Delta W_{z . b}=\lambda_{z} * W_{d}$,

$\Delta W_{d . b}=\lambda_{d} * W_{d}$,

In formula, $\Delta W_{n . s} \quad$--Demand-side avoidable electricity of the whole society,GW.h;

$\Delta W_{n . s . z} / \Delta W_{n . s . d}$--Demand-side lighting/ electric drive avoidable electricity of the whole society,GW.h;

$\Delta W_{z . b} / \Delta W_{d . b}$--Demand-side lighting/ electric drive avoidable electricity resources, GW.h; 
$W_{z} / W_{d} \quad$--Lighting/electric drive electricity consumption in 2017 in Huaian City,GW.h; Take the 2017 data as an example,From Fig. 1, in 2017, $W_{z}=61.91 \mathrm{GW} . \mathrm{h}, W_{d}=111.01 \mathrm{GW}$.h . Based on the assumption that the parameters are brought into the corresponding formula, we obtain:

$$
\begin{aligned}
& \Delta W_{z . b}=55.72 G W . h ; \Delta W_{d . b}=16.65 G W . h ; \Delta W_{n . s . z}=64.43 G W . h ; \Delta W_{n . s . d}=19.25 G W . h ; \\
& \Delta W_{n . s .}=23.18 G W . h ;
\end{aligned}
$$

It can be seen that in 2017, if $30 \%$ lighting and $20 \%$ motors were used in Huaian power grid, the whole society could avoid $23.18 \mathrm{GW} \cdot \mathrm{h}$ of electricity if a single mode of power demand management was adopted. It accounted for $13.4 \%$ of the total electricity consumption, and the effect of electricity saving is very remarkable.

\section{ANALYSIS ON ENERGY-SAVING BENEFIT OF IMPLEMENTING DEMAND-SIDE IN HUAIAN CITY}

DSM under the framework of the smart grid, should establish a more long-term, stable and sufficient DSM related projects to promote the implementation of incentive policies. To strengthen the publicity of the DSM project, for example, the electricity slip can be more intuitive to show the benefits of it. Under the framework of the DR, we should pay more attention to the choice of the demand side, strengthen the innovation of the electricity price variety, so that consumers can choose the most effective varieties according to their own consumption characteristics.For example,on the basis of time-sharing electricity price to increase the regional electricity price, more detailed division of the region, that is to say,in the same city to take sub regional electricity prices, to promote users away from the city center to increase electricity consumption.Moreover, we can launch "monthly electricity" form, then users according to their usual situation to purchase the corresponding electricity, it is similar to the flow of mobile phone purchase form, they should pay a relatively high unit price when using more than the amount of electricity purchased.

\section{CONCLUSIONS}

Smart grid is a complex and huge system engineering, including the generation, transmission, substation, distribution, electricity and scheduling, The core of its intelligence is a comprehensive and dynamic integration of user side resources.DSM as a tool for power company load management, it is a conform to the requirements of the electric power industry market reform and a reflection of the progress of the power system to use the DR to solve the power shortage problem. With the continuous development of smart grid, DSM should keep pace with the times, and constantly enrich the types of DR projects to provide a better serve for the entire power system and realize the effective utilization of resources.

\section{References}

[1] Yu Yongzhen. Demand Side Management, Electricity Price Reform and Energy Saving and Emission Reduction. Modern Economic Science, 2012.

[2] National Power Grid Corp demand side management guidance center. DSM technology[M]. China Electric Power Press, 2005.

[3] Jian Hong Gao.Demand Side Management under Smart Grid Framework. Journal of Shandong Electric Power College, 2010.

[4] Xiong Min, Zhou Zhaomao. The Development of Power Demand Side Management and Demand Response. Distribution \& Utilization, 2014.

[5] Q Zhang,X Wang. Smart grid from the perspective of demand response. Automation of Electric Power Systems, 2009.

[6] Yang Zhirong, Lao Derong.Demand-side Management(DSM) and its Application [M] , Beijing: China Power Press, 1999. 
